\title{
Digestive System Neuroendocrine Tumor by AJCC v7 Stage
}

National Cancer Institute

\section{Source}

National Cancer Institute. Digestive System Neuroendocrine Tumor by A/CC v7 Stage. NCI Thesaurus. Code C135129.

A term that refers to the staging of a digestive system neuroendocrine tumor, following the rules of the TNM AJCC V7 classification system. 